\title{
Triple Umbilical Incision for Videlaparoscopic Cholecystectomy
} \author{
Pedrozo Amarilla ${ }^{4}$ \\ ${ }^{1}$ Surgeon staff of Surgery Service-National Hospital of Itaugua, Paraguay \\ ${ }^{2}$ Surgeon staff of Urgency Surgery Service, National Hospital of Itaugua, Paraguay \\ ${ }^{3}$ Anesthesiology staff of Urgency Anesthesia Service, National Hospital of Itaugua, Paraguay \\ ${ }^{4}$ Unit coordinator of Surgical instrumenter Service, National Hospital of Itaugua, Paraguay
}

Héctor Rolando Herrera Cabral, ${ }^{1 *}$ Ángel Julián Acevedo Jara, ${ }^{2}$ Nelson Inocencio Ortellado Narvaez, ${ }^{3}$ Luz Analia

\begin{abstract}
Introduction: The laparoscopic surgery is done by using a single port. You place a device through a single incision between $18 \mathrm{~mm}$ to $50 \mathrm{~mm}$ and 3-4 trocars can be used. Our work consists of making 3 little incisions to put the three trocars which measure $5 \mathrm{~mm}$ and use conventional instruments that measure $36 \mathrm{~cm}$ of length of laparoscopic surgery within the internal limits of the umbilicus.
\end{abstract}

Objective: Describe the surgery technique and evaluate the initial results of a laparoscopic cholecystectomy option through three intraumbilical incisions.

Methods: It is a retrospective, descriptive, multicentre and observational study. Since June 2014 to August 2019, 20 patients, 17 females and 3 males, were operated using this method from the age ranges of 16 to 65 years old. The average surgical time was 65 minutes.

Results: In all cases the procedures were concluded by the intraumbilical approach. One of the cases had to be re-operated due to intraabdominal bleeding from the posterior branch of the cystic artery.

Conclusions: The technique is reproducible; the usual triangulation of the ports is not available. Therefore, fort this technique the surgeon needs to have experience and have had advanced training in laparoscopic surgery. The cases must be selective.

Keywords: triple incision, umbilicus and cholecystectomy

\section{Introduction}

The laparoscopy has appeared as one of the most significant advances in XX century surgery. Since Philippe Mouret has made the first videolaparoscopic cholecystectomy in 1985, the laparoscopy has become in the approach of choice for this technique, today it is the most commonly performed laparoscopic procedure in the world. ${ }^{1}$ The evolution of the minimally techniques invasive has led to the emergency of 2 new approaches and multiples intermediates routs, on the one hand, the surgery through natural anatomical or ifice (natural orifice transluminal endoscopic surgery (NOTES), ${ }^{2-5}$ and, for another hand, the surgery through a single incision (single incision laparoscopic surgery (SILSs) Single port, or currently called, laparoendoscopic single-site surgery (LESS), which most of the cases is the umbilicus, the embryological orifice that is repermeabilized to perform the intervention, (embryonic natural orifice transumbilical endoscopic surgery/LESS). So far, numerous procedures with multiple acronyms have been reported in the literature,

\begin{tabular}{|l|l|}
\hline Quick Response Code: & *Corresponding author: Héctor Rolando Herrera Cabral, Surgeon staff of Surgery Ser- \\
vice-National Hospital of Itaugua, Colón c/Aká Yuasá-Fernando de la Mora Zona Norte-Para- \\
guay \\
Received: 01 December, 2020 \\
Citation: Héctor RHC, Ángel JAJ, Nelson ION, Luz APA. Triple Umbilical Incision for Videlapa- \\
roscopic cholecystectomy. Surg Int Open Acc J. 2020;1(1):1-4. DOI: \\
10.53902/SIOAJ.2020.01.000501
\end{tabular}


however, the most acceptable seems to be LEES (From English: laparo-endoscopic single-site surgery) and whose translation into Spanish is laparoscopic surgery through a single port. ${ }^{4-6}$

This term covers all procedures that are performed through a single incision (usually between 18 and $50 \mathrm{~mm}$ ) and it includes multiples modalities such as: techniques that use multi-ports devices of different companies dedicated to the medical field (TriPort, Air Seal, Uni-X, SILs, X-Cone, Spider, etc. $)^{5-7}$ For the placement of some devices one must make incisions on average of $5 \mathrm{~cm} .5-6$ and in all of them we would have two major limitations: the agglomeration and interference of the instruments and the decrease in the quality of the triangulation and exposure of the surgical area, in addition some demand the realization of a broader incision. ${ }^{5,6,9}$ The technique that we present does not scape of these inconveniences, but it is economical to not use any devices that is placed in the umbilicus, nor the use of special instruments the objective is achieved which is the removal of the gallbladder and the aesthetic and cosmetic result is very acceptable since it does not leave visible marks.

\section{Material and Methods}

We present a retrospective study, multicentric and observational that includes 20 patients with symptomatic calculous cholecystopathy operated since June 2014 to August 2019. Of those 20 cases, 9 of them have been realized at the National Itaugua hospital and 11 cases in different private sanatories. They were 17 patients of female sex and 3 of male sex. The range of age was from 16 to 65 years old. Average 39.5 years old, the IMC average was of $24.2 \mathrm{~kg} /$ $\mathrm{m} 2$.

The criteria for patient's selection were:

1. IMC no more than $28 \mathrm{~kg} / \mathrm{m}^{2}$.

2. Do not present previous medium incision

3. Not having had previous ERCP

4. Do not present acute cholecystitis

5. Do not present calculus greater than $1 \mathrm{~cm}$.

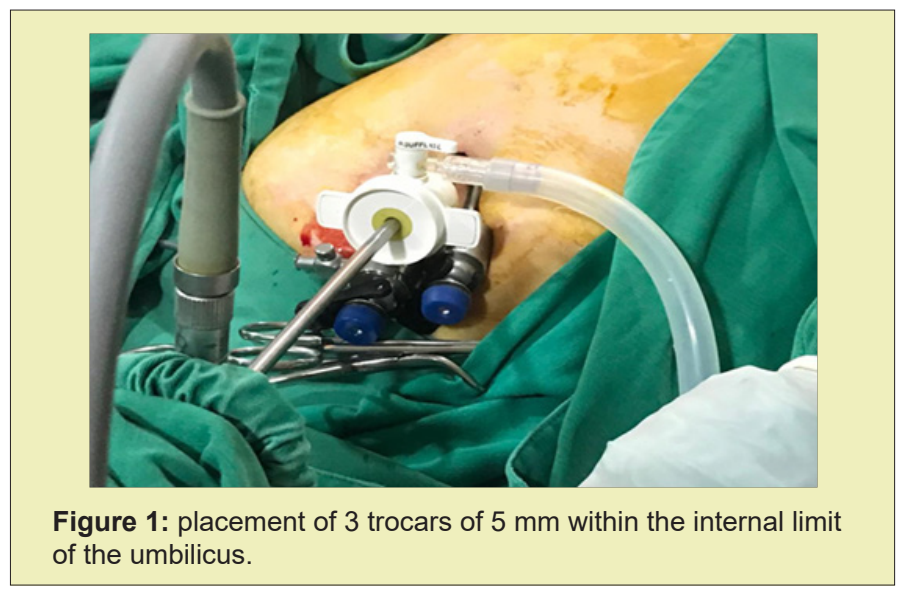

All patients received general anesthesia with intubation. The patient's position was with the legs open, with the surgeon between them and with an assistant to the right of the surgeon. The incisions that has been realized were: a superior median and two inferior lateral (similar to the Mercedes Benz star), all of $5 \mathrm{~mm}$. The creation of pneumoperitoneum has been realized by a Hasson technique modified in the superior trocar, then the other two sides are placed trying to introduce them with slight direction towards the sides, to try to save the superposition of instruments. The patient's position was in slight inverted Trendelenburg. It was placed a camera of $5 \mathrm{~mm}$ of $30^{\circ}$ in the superior port. In two cases we didn't had $5 \mathrm{~mm}$ clips applier, so one of the incisions was for a $10 \mathrm{~mm}$ trocar (Figures 1-3).

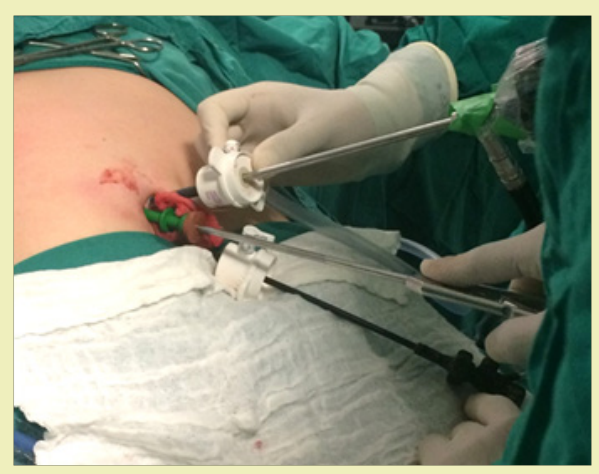

Figure 2: Moment where the needle of external point is received internally handled with the laparoscopic needle holder.

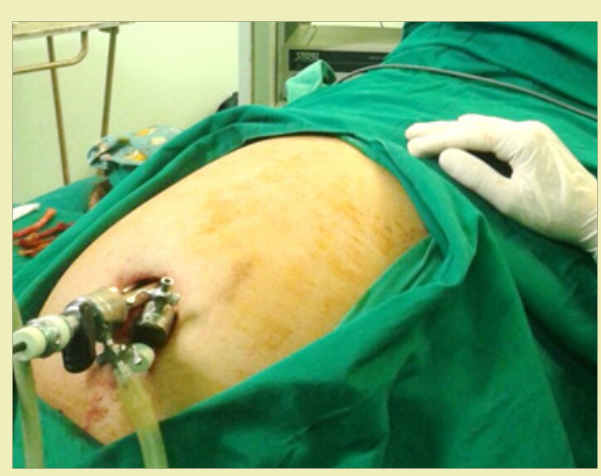

Figure 3: Use of a $10 \mathrm{~mm}$ trocar in the upper port.

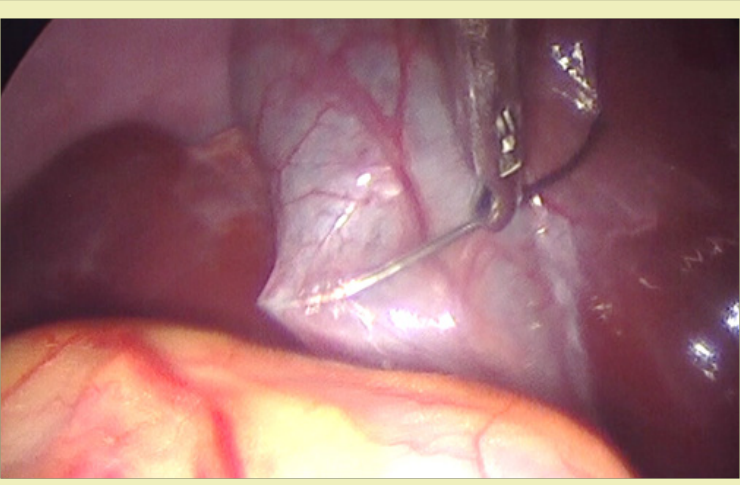

Figure 4: Placement of vesicular traction point at body level for exposure of the bile duct elements.

The first step was the traction of the vesicular fundus for which a point with a straight needle was placed at the right subcostal level crossing the entire abdominal wall that was recovered with a nee- 
dle holder inside the cavity, the gallbladder was presented carrying it towards the cranial and the intermediate point was placed between the fundus and the vesicular body. Trying to cover the same length without crossing the vesicular wall completely to avoid bile leakage. Then the needle was externalized recovering it next to the previous point. A knot was made on a petroleum jelly as a "button", to avoid marks due to ischemia on the skin (Figure 4). With the bottom pulled, the bile duct was exposed, bile tripod dissection began. Usually the optic was placed in the upper port but if necessary it was rotated to others ports, just as the use of the hook could be with the right or left hand in one or the other port, the same happened with the atraumatic clamp.

Once the element of the biliary tripod was identified and the critical vision was obtained (Figure 5) clipping was carried out with a $5 \mathrm{~mm}$ clipper and titanium clips, with 2 clips to the artery and 3 clips to the cystic duct. The artery was sectioned with electrocautery very close to the gallbladder, and the cystic duct was sectioned with scissors between the clips. Then we proceeded to deperitonize the vesicular fund where crossing the instruments seemed more pragmatic to us. The hemostasis was checked by introducing small cut gauze. The bottom thread was cut with scissors. The operative piece was removed by the upper trocar, it was performed under the vision of the camera that accompanied it until its next exteriorization. A small incision was made to enlarge the skin and the aponeurosis of a few millimeters in the lower direction for the removal of the operative piece, after aspirating or extracting stones if the case merited with Allis clamp, as if necessary closed the upper port aponeurosis with polyglactin 0 .

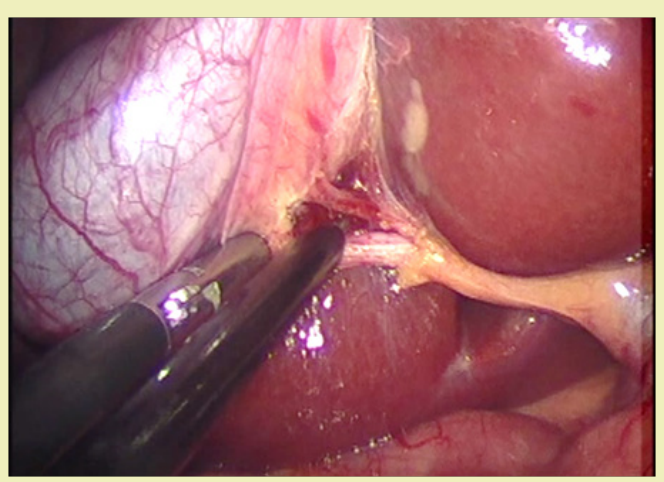

Figure 5: Critical view, where the cystic duct, cystic artery and the common bile duct can be seen.

All cases were realized by the method described. The operative time was between 40 to 100 minutes, with an average of 65 minutes. In all cases the surgery was completely by the method described. Of the 20 patients 19 reported a little post-operative pain and discharge was between 18 and 24 hours' post-operative. In one case there was a need for relasparocopy due to intra-abdominal hemorrhage, 6 hours after surgery, due to bleeding from the posterior branch of the cystic artery, it was a 41-year-old male patient whose gallbladder was with certain degree of chronic inflammation. For the relaparoscopy the trocars were placed regularly for a laparoscopy cholecystectomy. The patient was discharged at 48 hours (Table 1). The cuts inside the umbilicus when healing are imperceptible to the naked eye so aesthetically the method is very valid to leave no marks on the rest of the abdomen (Figure 6).

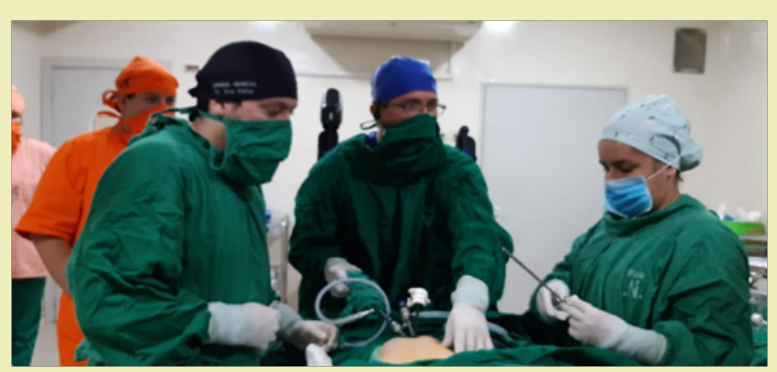

Figure 6: Surgeon did the surgery in standing wheelchair.

Table 1: Epidemiological and perioperative data

\begin{tabular}{|c|c|}
\hline Variables & Response \\
\hline Age (mean, range) & $39.5 / 16-65$ years old \\
\hline Sex (F/M) & $17-3$ \\
\hline Body mass Index (mean, range) & $24.2 / 19-27.8$ \\
\hline Symptomatic vesicular diseases & Cholecystopathy \\
\hline Crítical visión obtained & $19(95 \%)$ \\
\hline Procedure concluded successfully & $20(100 \%)$ \\
\hline cosmetic, esthetic results & $19(95 \%)$ \\
\hline post-operations complications & $1(5 \%)$ \\
\hline Operating time (mean, range) & $65 / 40-100$ min. \\
\hline cosmetic, esthetic results & $19(95 \%)$ \\
\hline Post-operations complications & $1(5 \%)$ \\
\hline
\end{tabular}

\section{Discussion}

The two most important limitations in most single-port laparoscopic surgery techniques are associated with decreased triangulation, exposure of the surgical area, and interference with the instruments inside the patient. ${ }^{6,10,11}$ The use of an external thread to expose the vesicular fund, also called the puppet method, ${ }^{4-12}$ it is useful to us if is not placed precisely in the vesicular fund, because being so, good traction and exposure of the bile duct is not achieved. Some authors therefore discard this method and use additional mini clamp, retraction with Kirschner wire or use of magnets for better exposure. ${ }^{10-13}$ We have considered that placing the non-transfixing point (to prevent bile leakage), but with good stitch length an adequate exposure of the bile duct is achieved an in intermediate area between the bottom and the body.

In 2008 we had the opportunity to be part of a study group where a single-port system called Spyder was used (Trasnterix Company) along with Dr. Aurora Pryor of Dukes University (Durham, North Carolina), who was at the front of the work, in the first 7 cases of cholecystectomies in humans, device $18 \mathrm{~mm}$ thick, which used a $5 \mathrm{~mm}$ camera of 0 degrees, a bottom clamp, and laterally 2 very flexible clamps similar to endoscopic clamps, which gained rigidity when placed in the working channel, it respects the triangulation, it was easy to use, but it uses specific instruments, special introduction device, therefore it is expensive..$^{7-14}$ What can be considered in the experiences of some authors is that some place an optics with 
a working channel, for the introduction of a dissector that both are handled by the surgeon, others place the trocars on the fingers of a glove attached to an Alexis, ${ }^{16}$ others prefer to place two external threads, and mobilize them to give traction to the elements to be dissected. ${ }^{4-12}$ The use of Kirschner nails for traction of the fundus and lateral of the gallbladder is also described. Other devices have built-in ports to place the instruments(SILS), sometimes specific with some curvature to save the triangulation. ${ }^{4-6}$ We use the normal instruments, (without any special intraumbilical introduction device) the optics in the upper trocar away and with a lot of zoom, thus avoiding the collision of instruments, and these grasp them in an inverted or lateral way with any of the hands.

\section{Conclusion}

For the successful realization of this procedure the patient's selection is very importance. An easily identifiable bile duct where the elements to be dissect are recognized by transparency is the ideal for a procedure where fear always lies in the injure of the main bile duct, the good exposure of the bile duct should be insisted with the external point that the vesicular body retracts, that should look good, then a slow dissection, without constraints, having a good critical view, and dissecting patiently. With these results we affirm that this technique of laparoscopy cholecystectomy with triple umbilical incision is a feasible, safe and effective technique. The esthetic and cosmetic result was very good since as the umbilicus is a natural scar and the small incisions over time merge with it and do not show any trace of the procedure. Is a reproducible procedure, although the surgeon who performs it should have an advanced training degree in laparoscopic surgery. The last patient we did the surgery in a standing wheelchair, because since 1 year 8 months the surgeon stayed in wheelchair (Figure 6\&7).

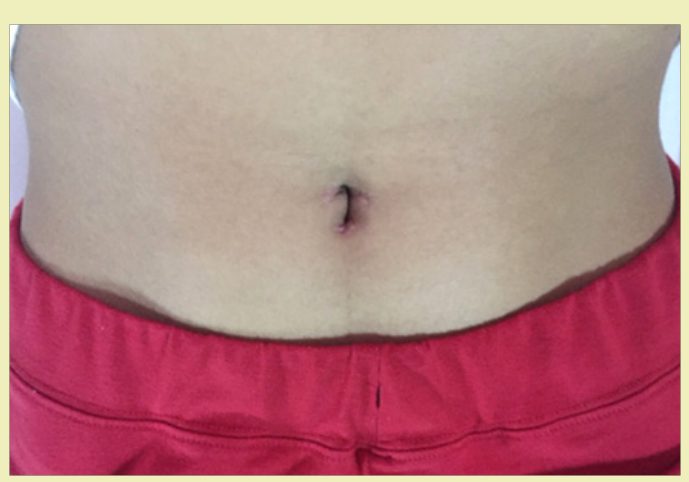

Figure 7: Cosmetic esthetic result, where you can see that the incisions are barely noticeable.

\section{Acknowledgments}

None.

\section{Funding}

None.

\section{Conflicts of Interest}

Author declares that there is no conflicto of interest.

\section{References}

1. Antonio García Ruiz, Leopoldo Gutiérrez Rodríguez, Jorge Cueto García. Evolución histórica de la cirugía laparoscópica. Cirugía endoscópica. 2016;17(2).

2. Zornig C, Mofid H, Emmermann A, et al. NOTES-Cholezystektomie ohne sichtbare Narben. Combined transvaginal and trans umbilical approach for cholecystectomy with no visible scarring. Klinische Studien. 2009;80(4):364-369.

3. Fuente SG, Demaria EJ, Reynolds JD, et al. New developments in surgery: Natural Orifice Transluminal Endoscopic Surgery (NOTES). Arch Surg. 2007;142(3):295-297.

4. Tacchino R, Grecco F, Matera D. Single-incision laparoscopic cholecystectomy: surgery without a visible scar. Surg Endosc. 2009;23(4):896-899.

5. Merchant AM, Cook MW, White BC, et al. Trans-umbilical Gelport access technique for performing single incision laparoscopic surgery (SILS). $J$ Gastrointest Surg. 2009;13:15916.

6. Jesús Garijo Alvareza, José, Daniel Sánchez Lópeza, Tomás González Elosuaa, et al. Colecistectomía laparoscópica transumbilical. Resultados con el dispositivo de gel y revisión. Cirugía Española. 2010;87(5):293298.

7. Aurora D Pryor, John R Tushar, Louis R DiBernardo. Single-port cholecystectomy with the TransEnterix SPIDER: simple and safe. Surg Endosc. 2010;24(4):917-923.

8. Rattner D, Kalloo A. ASGE/SAGES Working Group on Natural Orifice Transluminal Endoscopic Surgery. Surg Endosc. 2006;20(2):329-333.

9. Romanelli JR, Mark L, Omotosho PA. Single-port laparoscopic cholecystectomy with the TriPort system: a case report. Surg Innov. 2008;15(3):223-228.

10. Rane A, Dasgupta P. Single-incision laparoscopic surgery. BJU Int. 2009;103(4):429-430.

11. Canes D, Desai MM, Aron M, et al. Trans umbilical single-port surgery: evolution and current status. Eur Urol. 2008;54(5):1020-1029.

12. Roberts KE. True single-port appendectomy: first experience with the "puppeteer technique". SurgEndosc. 2009;23:182530.

13. Rafael Torres Peña, Javier Barreras González, Julián Ruíz Torres, et al. Colecistectomía laparoscópica a través de un puerto único. Revista Cubana de Cirugía. 2013;52(4)245-256.

14. Chan W Park, Hector R Herrera Cabral, Roberto J Manson, et al. Single port laparoscopic cholecystectomy with transenterix spider: early success in humans. SAGES. 2011.

15. Jorge Rodríguez, Gabriel Vial, Raúl herrera J, et al. Transumbilical laparoscopic cholecystectomy. Experience in 12 patients. Rev Chilena de Cirugía. 2010;62(1):33-36.

16. Michael William Parra, Fabián E Puentes-Manosalva, José Mauricio Suárez. Colecistectomía por laparoscopia de puerto único a través de un guante quirúrgico. Rev Colombiana Cir. 2011;26:56-61. 